\title{
CONGENITAL IDIOPATHIC HYPOGAMMAGLOBULINAEMIA
}

\author{
BY \\ K. M. PEARCE and M. S. PERINPANAYAGAM \\ From Hope Hospital, Salford, Lancashire
}

(RECEIVED FOR PUBLICATION MAY 6, 1957)

Since Bruton (1952) first described the syndrome of congenital agammaglobulinaemia associated with decreased resistance to infection in an 8-year-old boy, further cases in boys have been reported. Good and Mazzitello (1956) found 18 cases of congenital agammaglobulinaemia in the literature and described a further six cases in boys. Familial agammaglobulinaemia affecting male siblings has been described by Kulneff, Pedersen and Waldenström (1955) and by Elphinstone, Wickes and Anderson (1956). We have traced over 30 cases of congenital hypogammaglobulinaemia reported in boys but have only been able to find a few references to the syndrome in girls. Delaitre and Fonty (1955) reported congenital agammaglobulinaemia associated with recurrent infections in a 13-month-old girl, Arnaud-Battandier, Cabannes, Legendre and Sarfaty (1955) described the condition in a 16-monthold girl who died shortly after diagnosis, and Good and Zak (1956) mention a girl who appeared to be suffering from congenital agammaglobulinaemia but give no details.

Deficiency of serum gamma globulin has been reported in girls without any increased susceptibility to infection and Schick and Greenbaum (1945) reported this in an 11-year-old girl with oedema from birth.

There is at the time of writing one other female case of congenital hypogammaglobulinaemia included in the Medical Research Council's treatment trial for hypogammaglobulinaemia. This is a 3-year-old girl, but, unlike the case we report, she has no leucopenia or hepatosplenomegaly (Rubie, 1956).

\section{Case History}

M.S., now aged 3 years 8 months, was delivered normally at term on March 18,1953 . Her birth weight was $8 \mathrm{lb} .4 \mathrm{oz}$. and her neonatal period uneventful. She remained healthy until the age of 8 months.

She is the first child of unrelated, healthy parents. She has a sister aged 22 months who has always been healthy and a step-sister aged 6 years who had recurrent tonsillitis before tonsillectomy.

She was vaccinated against smallpox at the age of 4 months and gave a typical primary vaccinia response without complication. Diphtheria and pertussis immunization was completed at the age of 8 months.

From infancy she had had a history of constant infection.

November, 1953. Left otitis media. Spleen found to be enlarged.

December, 1953. Bronchitis and mild enteritis treated at home.

January, 1954. First admission to hospital. Recurrence of left otitis media and bronchopneumonia, signs mainly at the left base. Unsatisfactory response to penicillin, responded to aureomycin but relapsed and was finally controlled by streptomycin. Spleen and liver both palpable one fingerbreadth below the costal margins. Also normocytic, hypochromic anaemia, haemoglobin $60 \%$, no reticulocytosis. Bone marrow normal. No response to oral iron therapy. Haemoglobin, following $250 \mathrm{ml}$. of whole blood, rose to $90 \%$.

February, 1954, to February, 1955. Repeated upper respiratory infections and recurrent otitis media; two attacks of stomatitis; chickenpox and an illness diagnosed as measles.

March, 1955. A further attack of stomatitis, responded to local treatment. Haemoglobin $64 \%$, microcytic, hypochromic anaemia. No response to oral iron therapy.

April, 1955. Measles with recurrence of left otitis media. Second admission to hospital with chronic left otitis, purulent rhinitis, marked loss of weight, spleen palpable one fingerbreadth below costal margin. Haemoglobin $50 \%$. Infections responded to local treatment. Discharged home on oral iron therapy.

May, 1955. Third admission to hospital. Recurrence of purulent rhinitis with severe epistaxis, pyodermia of legs, liver palpable one fingerbreadth and spleen two fingerbreadths below costal margins. Bilateral palpable cervical lymph nodes. Haemoglobin $26 \%$, platelets normal. Infections failed to respond to penicillin, but responded to terramycin. Anaemia corrected by blood transfusion, and, following this, general condition improved. Bone marrow biopsy showed a hypoplastic reaction. On June 11, 1955, purulent rhinitis recurred, 
together with bilateral otitis media. These infections responded to penicillin. A two weeks' course of formyl tetrahydropteroylglutamic acid ('leucovorin') failed to improve the relative neutropenia. Haemoglobin was $88^{\circ}$ on discharge.

June, 1955. Ulcerative stomatitis, responded to local treatment at home. Spleen enlarged.

August, 1955, to November, 1955. Recurrent chronic left otitis media, recurrent rhinitis and bronchitis. Liver and spleen remained palpable two fingerbreadths below costal margins. Haemoglobin varied between $66 \%$ and $76 \%$.

December, 1955. Fourth admission to hospital. Exacerbation of left otitis media, and bronchopneumonia with right middle lobe consolidation. Liver and spleen enlarged as previously. Infections responded to terramycin. On January 3, 1956, she developed acute haemolytic streptococcal tonsillitis which responded to penicillin. Haemoglobin on discharge $84^{\circ} \circ$.

January, 1956. Gastro-enteritis, responded to treatment at home.

February, 1956, to April, 1956. Further upper respiratory infections, otitis media and bronchitis.

April, 1956. Fifth admission to hospital. Bronchopneumonia with consolidation at left base, chronic left otitis media and purulent vaginitis. Liver and spleen still enlarged. Palpable cervical lymph nodes. Infections responded to terramycin. Serum proteins were estimated and hypogammaglobulinaemia confirmed by paper electrophoresis. On April 22 recurrence of pneumonia which responded to penicillin. Haemoglobin $64 \%$. On June 5 exacerbation of left otitis media and rhinitis which responded to local treatment.

At this time the diagnosis was confirmed and treatment with intramuscular injections of gamma globulin was begun.

Pathological Investigations. The results of some of the haematological investigations related to her state of health during the period March, 1955, to November, 1956. are summarized in the table.

Plasma Proteins. April 12, 1956. Total serum protein $6.0 \mathrm{~g}$. per $100 \mathrm{ml}$. (albumin $4 \cdot 8$, globulin $1 \cdot 2, A: G$ ratio 4:1). Almost no turbidity was produced with zinc sulphate and paper electrophoresis showed no detectable gamma globulin (Fig. 1a). Examination by a photoelectric densitometer revealed a very small amount of gamma globulin (Fig. 1b). Dr. P. G. H. Gell failed to demonstrate the presence of gamma globulin by his immunochemical technique.

The levels of gamma globulin obtained on further serum by other methods of analysis varied but were all below $100 \mathrm{mg}$. per $100 \mathrm{ml}$.

May 2, 1956. Total serum protein $6 \cdot 16 \mathrm{~g}$. per $100 \mathrm{ml}$. Electrophoretic analysis: albumin $62 \cdot 1 \%$, alpha globulins $16.4 \%$, beta globulins $20 \%$, gamma globulin $1.6 \%$, $(98.6 \mathrm{mg}$. per $100 \mathrm{ml}$.). Estimation of gamma globulin by red blood cell agglutination technique gave a result of approximately $5 \mathrm{mg}$. per $100 \mathrm{ml}$.

Classical electrophoretic analysis carried out 13 weeks after treatment with gamma globulin was begun

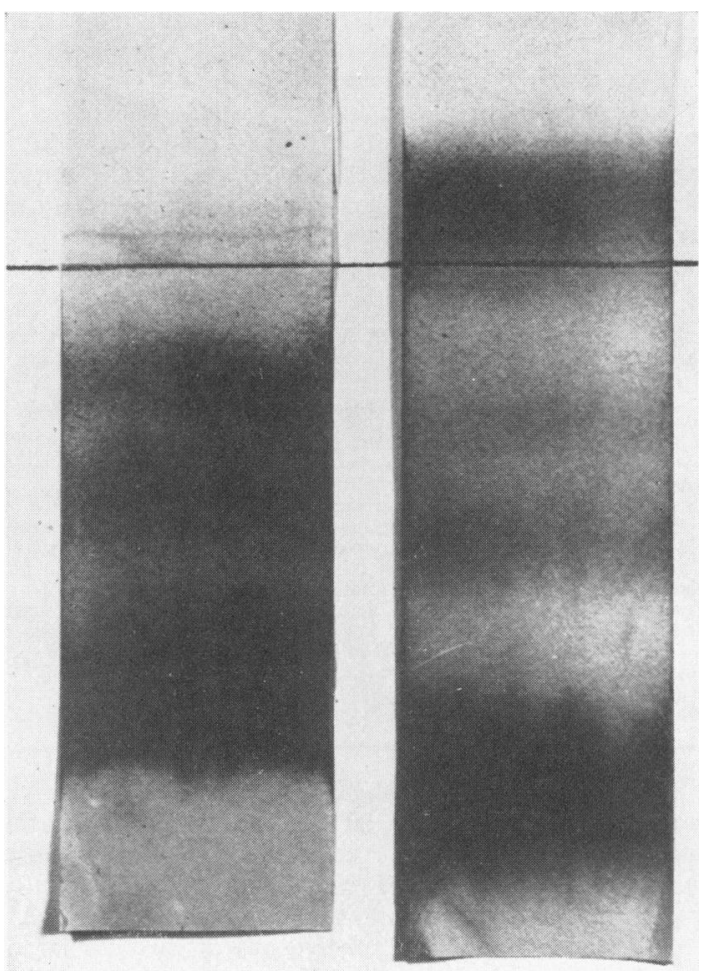

FIG. I(a). Paper electrophoresis (May, 1956) before beginning of treatment with gamma globulin.

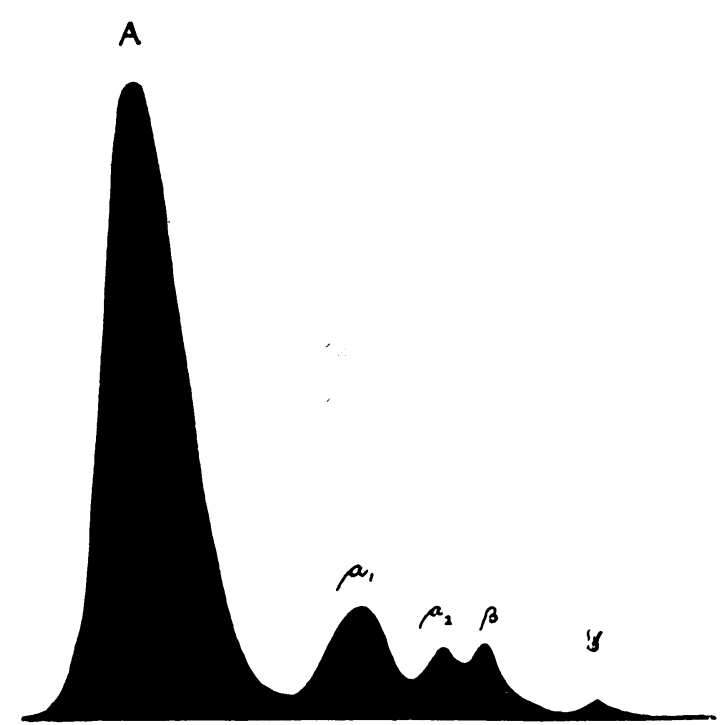

FIG. 1(b).-Graph obtained from 1(a) by examination with a photoelectric densitometer. 
gave the following results: albumin $69 \cdot 2 \%$, alpha globulin $7 \cdot 5 \%$, beta globulin $13.9 \%$, gamma globulin $1 \cdot 75 \%$. These figures represent the mean of the ascending and descending electrophoretic patterns (Fig. 2).

Paper electrophoresis after four, 12 and 24 weeks' treatment showed no appreciable change in the serum gamma globulin levels. Fig. 3 shows the pattern obtained on November 5, 1956, 24 weeks after the start of treatment. Estimations of serum proteins and electrophoresis of the patient's parents and sister were normal.

Serum Antibody Levels. The following results were obtained from tests on May 22, 1956.

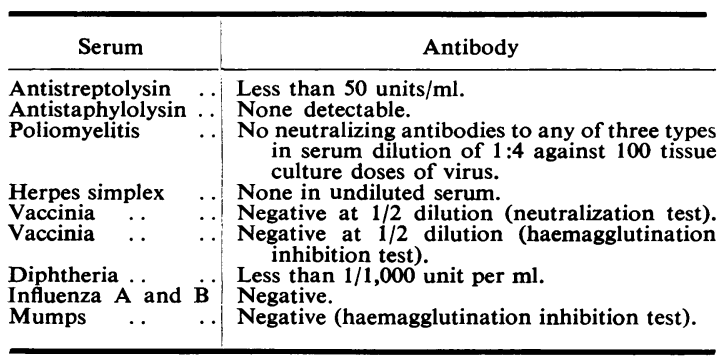

Biopsy of Cervical Lymph Node. A biopsy of a cervical lymph node on August 20, 1956, showed distortion of the normal follicular pattern and absence of plasma cells. In addition some areas of the sections showed granulomatous lesions without necrosis, the appearance of which was very suggestive of a tuberculous or sarcoid lesion. Search of Ziehl Neelsen-stained sections failed to reveal any evidence of tubercle bacilli.

Other Investigations. Culture of repeated nose and throat swabs failed to show that any particular organism was responsible for the infections.

On January 25, 1954, bone marrow biopsy showed a normal picture but on May 26, 1955, a hypoplastic reaction.

The blood group was A Rhesus positive. No anti-B isohaemagglutinins detectable. Liver function tests in April, 1956, including bromsulphthalein excretion tests, were normal.

Urine was normal.

The Schick test was positive on May 10, 1956.

Mantoux tests (1 in 1,000 on January 31, 1954, April 20 and December 15, 1955, 1 in 10 on October 29, 1956) were negative.

The clinical diagnosis of pneumonia was confirmed radiologically on three occasions. A radiograph of the chest 12 weeks after the start of treatment was normal.

Treatment. Treatment with intramuscular injections of pooled human gamma globulin was begun on May 23, 1956, the dosage given being in accordance with the Medical Research Council's trial in the treatment of hypogammaglobulinaemia.

In the first week she received $0.95 \mathrm{~g}$. per $\mathrm{kg}$. body weight on three occasions and thereafter this dosage was given once weekly for a period of four months.
In accordance with the trial the dosage was reduced to $0.025 \mathrm{~g}$. per $\mathrm{kg}$. body weight per week. She has now been receiving weekly injections of gamma globulin for a period of six months.

Progress. She has shown a satisfactory response to treatment and has had no major respiratory infections since the gamma globulin was begun in May, 1956. During the first nine weeks of treatment she remained very well, suffered no infections and gained $6 \mathrm{lb}$. in weight. Most striking of all was the change in her general health and behaviour. From being a child who previously had shown little interest in her surroundings or other children, she became an active, contented child who enjoyed playing with her friends. She had acute coryza at the beginning of August, 1956, but this infection resolved spontaneously without complications.

Anterior Poliomyelitis. On August 27, 1956, 14 weeks after the beginning of treatment with gamma globulin, she became anorexic and irritable, although when seen on this date she was apyrexial and had no localizing signs of infection. Four days later she was seen again because of weakness of the lower limbs and she was admitted to hospital with anterior poliomyelitis.

The symptoms before the onset of the paralysis were mild and when admitted her temperature was $98 \cdot 2^{\circ} \mathrm{F}$. and there was no complaint of headache, no neck stiffness and Kernig's sign was negative. She had some weakness of both lower limbs and the right knee jerk was diminished. The cerebrospinal fluid findings were as follows: leucocytes 160 per c.mm. (polymorphs $75 \%$, lymphocytes $25 \%$ ) protein $70 \mathrm{mg}$. \%, chlorides $700 \mathrm{mg}$. \%, sugar $57 \mathrm{mg}$. \%. She had a moderately severe paralytic illness with almost complete paralysis of both legs and a partial paralysis of the left arm. The paralysis was maximal on September 6, 1956, 12 days after the onset of the pre-paralytic symptoms. She was in the isolation hospital for five weeks and while there developed acute tonsillitis which responded to treatment with penicillin.

She returned to our care for physiotherapy on October 8, 1956, and shortly afterwards had a further attack of tonsillitis. This appeared to respond to terramycin, but a few days after treatment was discontinued the infection relapsed, necessitating the use of penicillin and streptomycin. Since November 1 she has had no further infections, although her temperature has never remained consistently normal. Twelve weeks after the onset of poliomyelitis she still has considerable residual muscle weakness of both lower limbs although recovery of function is continuing in response to 
physiotherapy. The paralysis of the left arm has almost completely recovered.

The enlargement of the liver and spleen began to recede from the time treatment was begun, and by August 1, 1956, the spleen was only just palpable below the costal margin. Since October 8 it has been impalpable. The liver still remains palpable but only one fingerbreadth below the costal margin. Since the fourth week of treatment the haemoglobin has shown a rise and varied between $76 \%$ and $84 \%$, and the total white cell count has on average been higher than before the administration of gamma globulin. There was still no significant leucocytosis at the time of the child's most recent infection.

\section{Discussion}

Agammaglobulinaemia is a metabolic disorder characterized by an increased susceptibility to bacterial infections, deficiency of gamma globulin in the serum, deficient antibody formation and failure of immunological response to antigenic stimulation. This syndrome is distinct from hypogammaglobulinaemia or agammaglobulinaemia

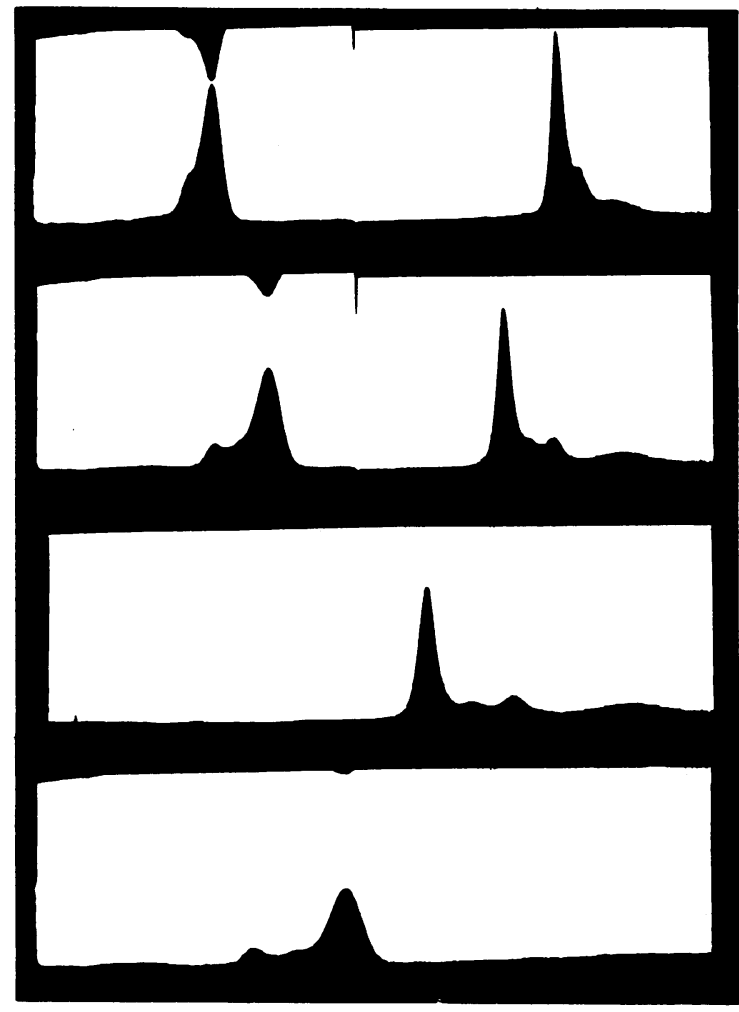

Fig. 2 -Classical electrophoresis (August, 1956).

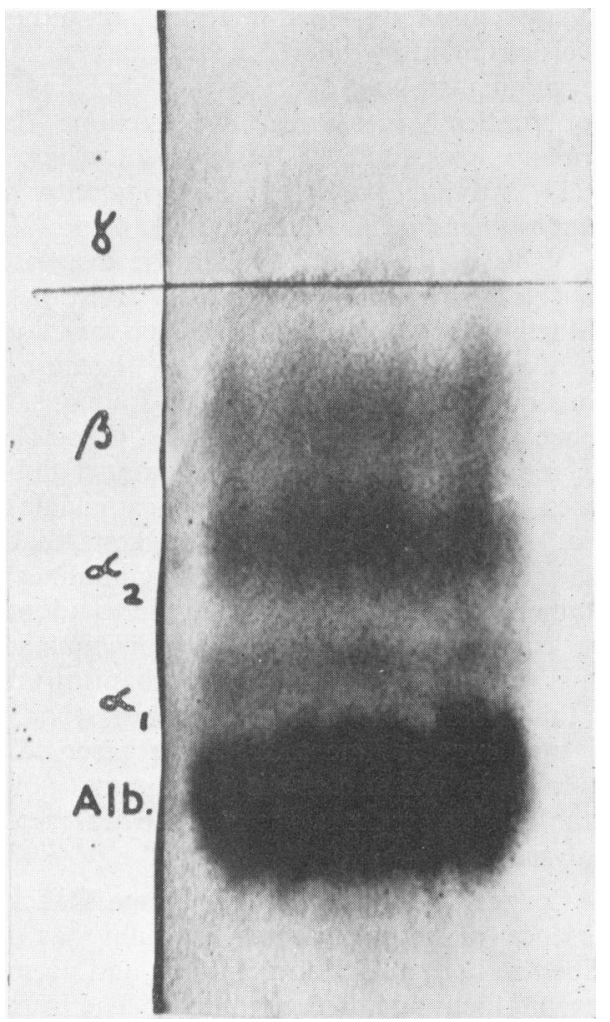

Fig. 3.-Paper electrophoresis (November, 1956), 24 weeks after beginning of treatment with gamma globulin.

occurring in other diseases such as the nephrotic syndrome, malnutrition and the syndrome of hypoproteinaemia and oedema associated with atrophic changes in the liver described by Thompson, McQuarrie and Bell (1936).

Agammaglobulinaemia or Hypogammaglobulinaemia. On inspection the original paper electrophoresis which led to the diagnosis in M.S. suggested a complete absence of gamma globulin (Fig. 1a) but when the paper was examined with a photoelectric densitometer a trace of gamma globulin was revealed (Fig. 1b). Dr. R. A. Kekwick confirmed this by electrophoretic analysis but Dr. P. G. H. Gell was unable to detect any gamma globulin by his immunochemical technique. Other methods of estimation showed varying but small amounts of gamma globulin.

When the earlier cases of this syndrome were described, gamma globulin was considered to be totally absent from the serum and the syndrome was designated 'congenital agammaglobulinaemia'. In recent cases more critical methods of analysis have 
shown small amounts of gamma globulin, although the levels obtained by different techniques vary.

The gamma globulin fraction may be separated electrophoretically into several sub-fractions (Cann, Brown and Kirkwood, 1949), each of which has antibody activity, but their precipitability with different antigens varies (Zinneman, Hall and Heller, 1954). This may possibly explain the disparity of values obtained by different methods of estimation. and Martin (1956) considers that the variation of levels of gamma globulin may be because the methods are estimating different sub-fractions. By the more critical methods of analysis, Good (1956) has demonstrated small amounts of gamma globulin in cases originally classified as agammaglobulinaemia. Although Good (1956) suggests that the popular usage of the term 'agammaglobulinaemia' be retained, it would be more accurate to adopt the term 'congenital idiopathic hypogammaglobulinaemia' until such time as the mechanism underlying this disorder is more fully understood, the term 'agammaglobulinaemia' being reserved for those cases in which there is no gamma globulin detectable in the serum by the more critical methods of analysis.

The Congenital Nature of the Syndrome. Deficiency or absence of serum gamma globulin has been described in both adults and children and occurs as a congenital and acquired condition. The transient hypogammaglobulinaemia of early infancy is a physiological phenomenon which under normal circumstances is of no clinical significance. The serum level of gamma globulin in full-term infants at birth is similar to that of the mother but falls to a minimum level at the age of 3 months (Orlandini, Sass-Kortsak and Ebbs, 1955). Thereafter it gradually rises, the normal adult level being approximated by 2 years of age.

Even though an infant is born with the inability to form its own gamma globulin and antibodies, sufficient of both of these may be transferred from the mother before birth to protect the infant from infection during the first few months of life. In the case reported here the onset of recurrent infections did not occur until the age of 8 months. This can be explained by the fact that up to this time a sufficiency of transferred gamma globulin was still present. Martin (1956) endorses this opinion.

We regard our case as congenital although the deficiency was not proved biochemically until the age of 3 years. It is interesting, however, that a year earlier her serum proteins were estimated because of suspected oedema and that at this time the total serum globulin was low (total serum protein
5.2 g. $\%$, albumin 4.0 g. $\%$, globulin 1.2 g. $\%$ ). Electrophoresis was not carried out on this occasion but it seems likely that the low total globulin was due to deficiency of the gamma fraction.

The Occurrence of the Syndrome in Females. The diagnosis of congenital hypogammaglobulinaemia is based mainly on the fact that the onset of infections was in infancy or early childhood. The earlier reported cases diagnosed on this basis were all males, and Janeway, Apt and Gitlin (1953) have postulated that the syndrome is inherited as a sex-linked recessive trait. The occurrence of the syndrome in females does not necessarily disprove this hypothesis, but there are probably two distinct groups of congenital hypogammaglobulinaemia. The first of these is confined to males, familial and inherited as a sex-linked recessive trait, and the second group, in which females may be affected, is inherited by a different genetic pattern in a similar way to 'haemophilia' in females or possibly arising as a result of a mutation. Hypogammaglobulinaemia has been reported in females under the age of 1 year (Harris and Schick, 1954; Homolka and Mydlil, 1955). These cases are probably infants in whom there has been an exaggeration of the normal physiological fall in serum gamma globulin. The agammaglobulinaemia in an 8-week-old girl, who died of generalized vaccinia following smallpox vaccination (Keidan, McCarthy and Haworth, 1953), was considered by Good and Mazzitello (1956) to be probably a pathological extension of the physiological hypogammaglobulinaemia of infancy. We have observed a premature infant with marked hypogammaglobulinaemia and susceptibility to respiratory infections of a transitory nature. This gives rise to a third group of cases in which the transient physiological hypogammaglobulinaemia is of such degree as to decrease the infant's resistance to infections. The low levels of serum gamma globulin would in these cases be of clinical significance for a transitory period, but the levels would return to normal later. This may be of particular importance in the case of premature infants, and further study is necessary to determine whether there is a critical level of serum gamma globulin below which susceptibility and lowered resistance to infections occurs.

In reviewing the literature it is clear that the nature of the recurrent infections and the organisms responsible may vary, but nearly all the male congenital cases have a history of recurrent major respiratory infections and our case is similar in this respect. The importance of considering hypogammaglobulinaemia in both male and female children who 
suffer from recurrent infections cannot be overstressed.

Haematological Changes and Hepatosplenomegaly. The leucocyte count (see Table) was consistently low, the total ranging from 4,300 to 5,100 per c.mm. during her infection-free periods. Even at the height of the infections the highest total count obtained was 9,100 per c.mm. The differential counts suggest that deficiency of both circulating polymorphs and lymphocytes was responsible for the low total counts but there was no consistent lymphopenia or neutropenia, there being considerable variation in the differential counts on different occasions. Leucopenia has frequently been described in hypogammaglobulinaemia, and failure of leucocytosis during infections is well recognized. The explanation remains obscure but Rosecan, Trobaugh and Danforth (1955) have suggested that it may be caused by a lack of some component of gamma globulin which is necessary for the elaboration of the leucocytosis-promoting factor isolated by Menkin (1950). If this is accepted then the leucopenia is an essential part of the hypogammaglobulinaemia syndrome in children. However, we are of the opinion that the leucopenia in M.S. is more likely to be a secondary phenomenon. A leucocytosis of over 20,000 cells per c.mm. was discovered in a 3-year-old girl with hypogammaglobulinaemia without splenomegaly (Rubie, 1956) and the findings in our case suggest that the leucopenia and splenomegaly may be related.
A feature of particular interest in our case was the presence of hepatosplenomegaly. Enlargement of the spleen has been described previously in cases of hypogammaglobulinaemia (Grant and Wallace, 1954, Rohn, Behnke and Bond, 1955; Good and Mazzitello, 1956), and the suggestion has been put forward by Grant and Wallace that it represented a reactive hyperplasia of the reticulo-endothelial system. The reticulo-endothelial cells of the liver and spleen both play an important part in the complex process of antibody formation and they are indirectly involved in the production of the gamma globulin fraction.

In M.S. the spleen was definitely enlarged at the time of her first infection at the age of 8 months. The splenomegaly can hardly be dismissed as 'the result of her recurrent infections', neither can the hepatomegaly be explained on these grounds, and in the absence of any evidence of hepatic dysfunction we regard the hepatosplenomegaly as a reactive hyperplasia. This theory is supported by the fact that since she began treatment with gamma globulin the spleen and liver have both receded and the spleen is no longer palpable.

We have already referred to the possible association of the leucopenia and splenomegaly, and suggest that the leucopenia may be due to secondary hypersplenism. Another possible explanation is that the recurrent infections caused depression of the leucopoietic elements of the bone marrow. The improvement in the leucocyte count after treatment

TABLE

RESULTS OF SOME HAEMATOLOGICAL INVESTIGATIONS RELATED TO PATIENT'S STATE OF HEALTH

\begin{tabular}{|c|c|c|c|c|c|c|c|c|c|c|}
\hline Date & Age & State of Health & 总 & 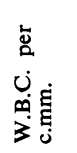 & 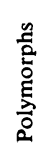 & 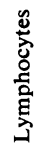 & 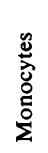 & 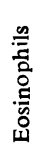 & 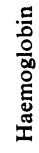 & 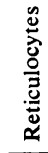 \\
\hline 5. 1.54 & $9 \frac{1}{2}$ mth. & Bronchopneumonia and left otitis & & & 49 & & & & & \\
\hline $\begin{aligned} \text { 20. } 1.54 \\
1.3 .55 \\
14.55\end{aligned}$ & 10 mth. & $\begin{array}{lll}\text { media } & \cdots & \cdots \\
\text { Welapse of pneumonia } & \cdots & \cdots \\
\text { Exacerbation of otitis media and }\end{array}$ & $\begin{array}{l}104 \\
105 \\
\text { Normal }\end{array}$ & $\begin{array}{l}7,200 \\
4,300\end{array}$ & $\begin{array}{l}49 \\
31 \\
51\end{array}$ & $\begin{array}{l}43 \\
63 \\
40\end{array}$ & $\begin{array}{l}8 \\
5 \\
9\end{array}$ & 1 & $\begin{array}{l}60 \\
60 \\
64\end{array}$ & $\begin{array}{l}1 \cdot 2 \\
1 \cdot 2 \\
-\end{array}$ \\
\hline 14. 4.03 & 2 yrs. $1 \mathrm{mth}$. & $\begin{array}{c}\text { Exacerbation of otitis media and } \\
\text { purulent rhinitis } \ldots\end{array}$ & $101 \cdot 3$ & 9,100 & 一 & - & - & & 50 & - \\
\hline 26. 5.55 & 2 yrs. $2 \mathrm{mth}$. & $\begin{array}{l}\text { Infection not responding to penicillin. } \\
\text { Started on terramycin }\end{array}$ & & 4,300 & 34 & 54 & 12 & & 50 & 0.6 \\
\hline $\begin{aligned} & 31 . 5.55 \\
& 24 . 8.55 \\
& 8.12 .55\end{aligned}$ & $\begin{array}{l}2 \text { yrs. } 5 \mathrm{mth} . \\
2 \text { yrs. } 9 \mathrm{mth} .\end{array}$ & $\begin{array}{l}\text { Infection controlled. Well } \ldots \\
\text { Very well } \ldots \\
\text { Bronchopneumonia and otitis media }\end{array}$ & 104 & $\begin{array}{l}4,300 \\
4,500 \\
8,100\end{array}$ & $\begin{array}{l}31 \\
60 \\
-\end{array}$ & $\begin{array}{l}64 \\
36 \\
-\end{array}$ & $\begin{array}{r}5 \\
4 \\
-\end{array}$ & & $\begin{array}{l}56 \\
76 \\
78\end{array}$ & $\begin{array}{l}2 \cdot 0 \\
3 \cdot 0\end{array}$ \\
\hline 28. 3.56 & 3 yrs. & $\begin{array}{l}\text { Upper respiratory infection and } \\
\text { chronic otorrhoea }\end{array}$ & & 5,800 & 57 & 35 & 7 & 1 & 66 & - \\
\hline 12. 4.56 & 3 yrs. $1 \mathrm{mth}$. & $\begin{array}{c}\text { Bronchopneumonia, otitis and puru- } \\
\text { lent vaginitis }\end{array}$ & 103 & 7,000 & 68 & 27 & 5 & & 70 & - \\
\hline $\begin{aligned} & \text { 23. } 4.56 \\
& \text { 2. } 5.56\end{aligned}$ & & $\begin{array}{l}\text { Relapse of pneumonia } \\
\text { Exacerbation of otitis media and }\end{array}$ & 101 & 7,200 & 62 & 35 & 2 & 1 & 64 & - \\
\hline 14. 6.56 & 3 yrs. 3 mth. & $\begin{array}{lcccc}\text { purulent rhinitis } & \ldots & & . & \\
\text { Well } & . & \ldots & & \\
\text { No }\end{array}$ & $\begin{array}{l}101 \\
\text { Normal } \\
\text { Normal }\end{array}$ & $\begin{array}{l}8,700 \\
6,400 \\
5,900\end{array}$ & $\begin{array}{l}67 \\
47 \\
\end{array}$ & $\begin{array}{l}30 \\
44 \\
\end{array}$ & $\begin{array}{r}3 \\
8 \\
-\end{array}$ & 1 & $\begin{array}{l}70 \\
68 \\
76\end{array}$ & $\overline{0.6}$ \\
\hline 17. 9.56 & 3 yrs. 6 mth. & Recovering from poliomyelitis & Normal & 8,400 & - & $=$ & - & & 76 & - \\
\hline 9.10 .56 & & $\begin{array}{llllll}\text { Well } & \because & \ldots & \ddots & \ldots & \ldots\end{array}$ & Normal & 8,000 & 62 & 30 & 8 & & 84 & - \\
\hline $\begin{array}{r}29.10 .56 \\
6.11 .56\end{array}$ & 3 yrs. $8 \mathrm{mth}$. & $\begin{array}{l}\text { Recovering from tonsillitis } \\
\text { No infection localized }\end{array}$ & $\begin{array}{l}100 \cdot 2 \\
100\end{array}$ & $\begin{array}{l}6,200 \\
5,300\end{array}$ & $\begin{array}{l}75 \\
71\end{array}$ & $\begin{array}{l}17 \\
22\end{array}$ & $\begin{array}{l}8 \\
7\end{array}$ & & $\begin{array}{l}80 \\
76\end{array}$ & 二 \\
\hline
\end{tabular}




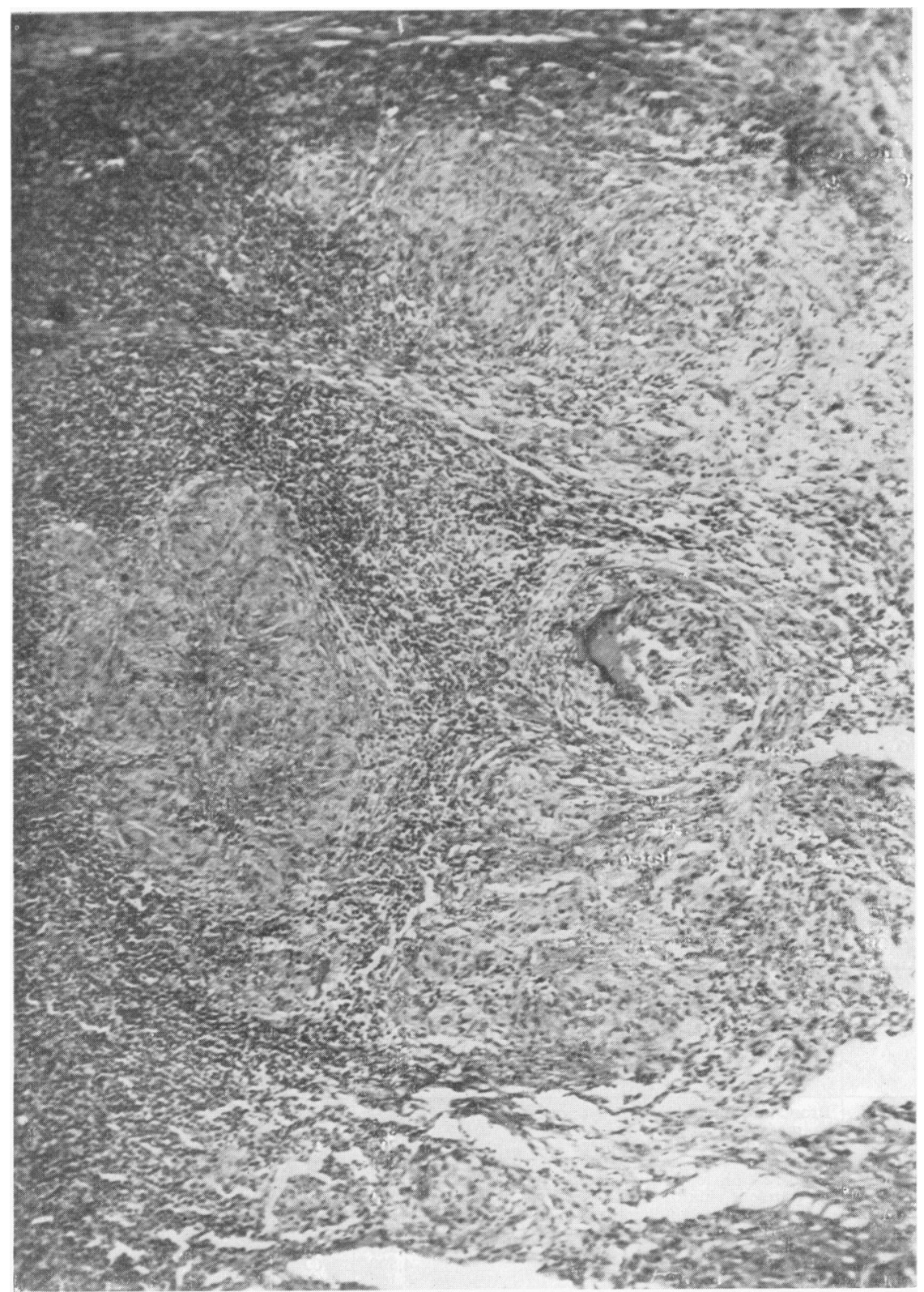

FIG. 4.-Photomicrograph of section of cervical lymph node.

would support either theory, but up to the time of writing we have not had the opportunity to study the leucocyte response to any proved major bacterial infection.

So far we have not discussed the behaviour of the haemoglobin. The haemoglobin values before treatment frequently revealed a moderate anaemia, the red cells showing on some occasions slight anisocytosis, microcytosis and hypochromia. The colour index when this was estimated was in the region of 0.92 . The anaemia was not influenced by oral iron therapy and on two occasions blood 
transfusions were considered necessary. The hypoplastic reaction of the bone marrow suggests that the anaemia was secondary to the recurrent infections. There was never any significant reticulocytosis and investigations never showed any evidence of haemolysis. Since the administration of gamma globulin the haemoglobin level has remained within normal limits.

The Histological Findings in a Lymph Node. Good (1954, 1955) described the absence of plasma cells from bone marrow and lymph nodes in hypogammaglobulinaemia. He studied the response of the marrow and lymph nodes to antigenic stimulation and found no evidence of plasma cell formation associated with deficient antibody formation in cases of hypogammaglobulinaemia.

A cervical lymph node removed from M.S. was reported as showing a complete absence of plasma cells and distortion of the follicular pattern. In addition some areas were very suggestive of a tuberculous or sarcoid lesion. Examination of Ziehl-Neelsen stained sections failed to reveal any evidence of tubercle bacilli. Mantoux tests ( 1 in $1,000)$ carried out when she was 10 months, 2 years 1 month, and 2 years 9 months of age were negative and she is still 'Mantoux negative' at a dilution of 1 in 10 . It is difficult to explain the findings of areas in the sections which have the appearance of a tuberculous lesion as being caused by tuberculous infection in view of the negative Mantoux reactions unless deficiency of gamma globulin is responsible for failure of 'conversion'. Elphinstone et al. (1956) report a child in whom tuberculous infection occurred after the symptoms of hypogammaglobulinaemia had begun, and in whom conversion of the Mantoux was observed. The Mantoux, 1 in 10,000 in their case, was still positive three years later after the diagnosis of 'agammaglobulinaemia' had been established. The results of Mantoux tests in previously reported cases of congenital hypogammaglobulinaemia have not always been recorded and further study is necessary to establish definitely the behaviour of the Mantoux reaction in this syndrome. Our case gives no history of known contact with tuberculosis and there has never been any reason to suppose that she had a tuberculous cervical adenitis. Although the appearance of the lymph node sections suggests tuberculosis it seems unlikely that the lesion was caused by the tubercle bacillus. The absence of plasma cells and disorganization of the follicular pattern are the histological findings in lymph nodes from cases of congenital hypogammaglobulinaemia (Martin, 1957) but the presence of a granulomatous lesion is an unusual feature.

Zinneman et al. (1954) reported a case of acquired agammaglobulinaemia in a 30-year-old female with splenomegaly, leucopenia and anaemia, in whom biopsy of lymph nodes and liver revealed the presence of epithelioid cell granulomas without necrosis. In this case splenectomy was performed for hypersplenism and the spleen also showed numerous granulomas. They considered a probable diagnosis of Boeck's sarcoid and that the agammaglobulinaemia was secondary. It is possible that these lesions may be a histological feature in some cases of congenital or acquired hypogammaglobulinaemia or alternatively they may be the result of infection by some unknown agent. A primary diagnosis of sarcoidosis might have been considered in our case if the deficiency of serum gamma globulin had not been detected earlier.

The Circulating Antibody Levels. There is strong evidence to suggest that the circulating antibodies in man are produced by the plasma cells (Good, 1955). Most of the antibodies and isohaemagglutinins are found in the gamma globulin fraction of the plasma proteins (Cohn, Oncley, Strong, Hughes and Armstrong, 1944) and deficiency of antibody production, associated with absence of plasma cells, is an essential feature of the hypogammaglobulinaemia syndrome. No significant amounts of any of the antibodies estimated were present in the serum of M.S. before treatment with gamma globulin. Antibody formation following antigenic stimulation has not been studied in detail but we did, however, have the opportunity to observe her clinical and immunological response to anterior poliomyelitis.

Response to Anterior Poliomyelitis. This infection occurred 14 weeks after the beginning of treatment when she was receiving $750 \mathrm{mg}$. of gamma globulin weekly. This gamma globulin was known to contain antibodies to types I, II and III poliomyelitis viruses, but despite this she had a severe paralytic illness. This does not necessarily raise doubts as to the value of gamma globulin in poliomyelitis prophylaxis, for in M.S. its administration may well have prevented a more severe or even fatal illness, but it seems reasonable to suppose that larger doses of gamma globulin are required to effect prophylaxis in cases of hypogammaglobulinaemia.

Before treatment no neutralizing antibody to any of the three types of poliomyelitis virus was detectable in a 1 in 4 dilution of her serum. Type $I$ poliomyelitis virus was isolated from the faeces 
during the paralytic phase of the illness but there was subsequently no significant rise in the type I antibody titre. Eight weeks after the onset of infection, antibodies to all three types of virus were detected in her serum at a dilution of 1 in 10.

This equal rise of the antibody levels to all three types of virus is probably due to the administration of gamma globulin over a long period, and suggests that she was unable to produce any antibodies of her own, for one would expect to find a very high antibody titre in a normal child eight weeks after infection.

\section{Summary}

The first case of congenital idiopathic hypogammaglobulinaemia in a girl in England is described, and her progress during the first six months of treatment with gamma globulin is reported.

She is aged 3 years 8 months and has a history of recurrent infections since the age of 8 months; shows deficient antibody formation and a failure of immunological response to antigenic stimulation by type I poliomyelitis virus.

A cervical lymph node exhibits the characteristic feature of absence of plasma cells, and the finding of changes resembling a tuberculous or sarcoid lesion are discussed.

The significance of associated leucopenia, anaemia and hepatosplenomegaly are discussed.

The clinical and immunological response to anterior poliomyelitis, occurring during the fourteenth week of treatment with gamma globulin, is commented on.

Attention is drawn to a pathological extension of the normal physiological hypogammaglobulinaemia of infancy and its possible significance in prematurity.

The reasons for preferring the term 'congenital idiopathic hypogammaglobulinaemia' to 'agammaglobulinaemia' are given and the importance of considering the diagnosis of hypogammaglobu- linaemia in both female and male children with a history of recurrent infections is stressed.

We wish to thank Dr. R. I. Mackay for permission to publish this case, and for his help and advice; Professor N. H. Martin for his helpful advice and criticism and for the slides and photomicrograph of the lymph node and the classical electrophoretic analysis; Dr. P. O. Williams for his interest and cooperation; Dr. R. A. Kekwick and Dr. P. G. H. Gell for some of the gamma globulin estimations and Dr. F. O. MacCallum for the estimations of the antibody levels and isolation of the poliomyelitis virus. We also thank Dr. G. J. Crawford and his staff for the pathological investigations, particularly Mr. F. Warburton for the paper electrophoresis and photographs in Figs. 1 and 3; Dr. Hall of Ladywell Isolation Hospital for cooperation; Mrs. J. Harrison for secretarial assistance and the nursing staff of Hope Hospital, Salford, for their sympathetic care of M.S. during her periods in hospital.

\section{REFERENCES}

Arnaud-Battandier, R., Cabannes, R., Legendre, E. and Sarfaty, R (1955). Pédiatrie, 10, 880 .

Bruton, O. C. (1952). Pediatrics, 9, 722.

Cann, J. R., Brown, R. A. and Kirkwood, J. G. (1949). J. biol. Chem., 181, 161.

Cohn, E. J., Oncley, J. L., Strong, L. E., Hughes, W. L. Jr. and Armstrong, S. H. Jr. (1944). J. clin. Invest., 23, 417.

Delaitre, R. and Fonty, P. (1955). Bull. Soc. méd. Hôp. Paris, 71, 239.

Elphinstone, R. H., Wickes, I. G. and Anderson, A. B. (1956). Brit. med.J., 2, 336.

Good, R. A. (1954). A.M.A. J. Dis. Child., 88, 625.

- (1955). J. Lab. clin. Med., 46, 167. and Mazzitello, W. F. (1956). Dis. Chest., 29, 9.

and Zak, S. J. (1956). Pediatrics, 18, 108.

Grant, G. H. and Wallace, W. D. (1954). Lancet, 2, 671.
Harris, J. R. and Schick, B. (1954). J.Mt Sinai Hosp., 21, 148.

Homolka, J. and Mydlil, V. (1955). Csl. Pediat., 10, 362.

Janeway, C. A. (1954). Summary of Seminar on Gamma Globulin. International Children's Centre (Paris, 1954). Apt, L. and Gitlin, D. (1953). Trans. Ass. Amer. Phys., 66,

Keidan, S. E., McCarthy, K. and Haworth, J. C. (1953). Archives of Disease in Childhood, 28, 110.

Kulneff, K., Pedersen, K. O. and Waldenström, J. (1955). Schweiz. med. Wschr., 85, 363.

Martín, N. H. (1956). Personal communication.

- (1957). In Lectures on the Scientific Basis of Medicine, Vol. 5. London.

Menkin, V. (1950). Newer Concepts of Inflammation, 1st ed., No. 70. Springfield, Illinois.

Orlandini, O, Sass-Kortsak, A. and Ebbs, J. H. (1955). Pediatrics, 16, 575 .

Rohn, R. J., Behnke, R. H. and Bond, W. H. (1955). Amer. J. med. Sci., 229, 406.

Rosecan, M., Trobaugh, F. E. and Danforth, W. H. (1955). Amer. J. Med., 19, 303 .

Rubie, J. (1956). Personal communication.

Schick, B. and Greenbaum, J. W. (1945). J. Pediat., 27, 241.

Thompson, W. H., McQuarrie, I. and Bell, E. T. (1936). Ibid., 9, 604.

Zinneman, H. H., Hall, W. H. and Heller, B. I. (1954). J. Amer. 